\title{
A Facile Transformation of Amino acids into 1,4-dihydropyridines and their Crystallographic Analysis
}

Anindita Adak ${ }^{*[a]}$ and Puneeth Koppal[a]

[a]Department of Chemistry, Indian Institute of Science Education and Research-Pune, Dr. Homi Bhabha Road, Pashan, Pune-411 008.

E-mail: aninadak@students.iiserpune.ac.in

\begin{abstract}
A facile transformation of amino acids into substituted 1,4-dihydropyridines (1,4DHP) is reported. The natural amino acids were converted into $\gamma$-amino $\beta$-keto esters and used for the synthesis of substituted 1,4-dihydropyridines from the Hantzsch reaction. Using amino acids as starting materials, a variety of dihydropyridine derivatives have been synthesized and isolated in good yields. This method is found to be efficient and compatible with various amino acid side-chains and amine protecting groups. Results reported here suggested that amino acids can be used to synthesize highly versatile heterocyclic 1,4-dihydropyridine derivatives, without using any catalyst.
\end{abstract}

Keywords: amino acids $\bullet$ condensation $\bullet$ cyclization $\bullet$ dihydropyridines $\bullet$

\section{Introduction}

Amino acids are essential components for the existence of life on earth and they are responsible for the structure and function of proteins. Besides their biological role, they have been serving as starting materials for the synthesis of various drugs intermediates, ${ }^{1}$ chiral catalyst, ${ }^{2}$ heterocyclic compounds, ${ }^{3}$ statins, ${ }^{4} \beta$-amino acids, ${ }^{5} \gamma$-amino acids, ${ }^{6}$ and biodegradable polymers. $^{7}$

1,4-Didropyridine(1,4-DHP) is a semi saturated nitrogen-containing heterocyclic compound derived from pyridine as a parent molecule. As the scaffold of 1,4-dihydropyridine is the main constituent of many small molecule-based drugs, it emerged as one of the very important molecules in the pharmaceutical industry. ${ }^{8}$ Several substituted 1, 4-DHP derivatives containing drugs are clinically accepted as cardiovascular agents and they have been using for the treatment of hypertension such as nicardipine, amlodipine, nifedipine etc. ${ }^{9}$ Some of the drugs containing DHP derivatives are shown in Figure 1. In addition, 1,4-DHP derivatives have also been used as antioxidant, ${ }^{10}$ antimalarial, ${ }^{11}$ antibacterial, ${ }^{12}$ antifungal, ${ }^{13}$ antiplasmodial, ${ }^{14}$ anti- 
inflammatory, ${ }^{15}$ and antidiabetic agents. ${ }^{16}$ Besides, they have also shown promising potential as HIV protease inhibitor, ${ }^{17}$ anti-ischemic agents for treating Alzheimer's disease ${ }^{18}$ chemo sensitizers in tumour therapy, ${ }^{19}$ platelet antiaggregatory agents, ${ }^{20}$ bronchodilators for treating tuberculosis, ${ }^{21}$ cystic fibrosis, ${ }^{22}$ asthma ${ }^{23}$ and neuroprotective agents in neuronal diseases. ${ }^{24}$

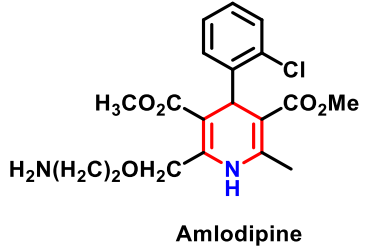

Amlodipine

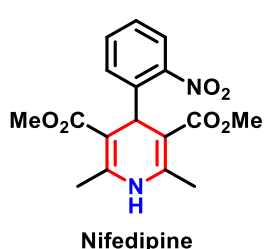

Nifedipine

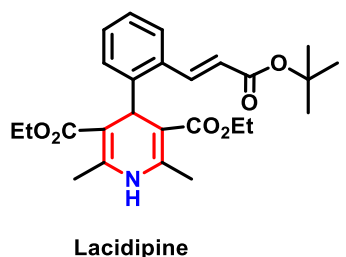

Lacidipine

Figure 1: Drugs containing 1,4-DHP moieties present in the market.

Besides exhibiting biological activity these are well known as NADH bio-mimic and provides many examples of well-known hydride donors for reduction of alpha-keto electronwithdrawing conjugated olefins, cyclic enones, ketones to alcohols and hydrogenation of alphabeta unsaturated aldehydes and imines etc. ${ }^{25}$

Due to its wide applications, numerous methods have been developed for the synthesis of 1, 4DHP derivatives. The classical Hantzsch method involving cyclo condensation of two equivalents of keto esters, aldehyde and ammonia as a nitrogen source by refluxing in water has been extensively used to synthesize 1,4-DHP derivatives. ${ }^{26}$ In addition to the Hantzsch method, various new methods and catalysts including lewis acid, ${ }^{27}$ bronsted acids, ${ }^{28} \mathrm{PhB}(\mathrm{OH})_{2}$ and $\mathrm{PPH}_{3},{ }^{29}$ metal triflates, ${ }^{30}$ molecular iodine,${ }^{31}$ organocatalysts, ${ }^{32}$ TMS iodide, ${ }^{33}$ and ionic liquids $^{34}$ have been developed to improve the yield of the reaction. Using these methods, numerous derivatives of 1,4-DHP have been synthesized and studied. However, no method is reporting in the literature for the direct introduction of amino acid functional groups on the 1,4DHP. This is possibly due to the lack of the commercial availability of starting material amino beta-keto esters. The amino acid functional groups may improve the biological activities of these DHP derivatives.

We have been working in the area of foldamers composed of various types of unnatural $\gamma$ amino acids. Besides their utility in the design of foldamers, these unnatural amino acids such as $\alpha, \beta$-unsaturated $\gamma$-amino acids and $\gamma$-amino $\beta$-keto esters have served as starting materials for the construction of various small molecules. Recently, we demonstrated the synthesis of $\gamma$-lactams from $\alpha, \beta$-unsaturated $\gamma$-amino amides through a base mediated molecular rearrangement. ${ }^{35}$ The $\gamma$-amino $\beta$-keto esters have been used to synthesize functionalized curcumins and fluorescent amino acids, ${ }^{36} \gamma$-amino $\beta$ - hydroxy amino acids, ${ }^{37}$ and symmetrical 
tetra-substituted pyrazines through air oxidation. ${ }^{38}$ We envisioned that the amino acidfunctionalized 1,4-DHP derivatives can be synthesized using $\gamma$-amino $\beta$-keto esters. We herein are reporting the synthesis of amino acid-functionalized 1,4-dihydropyridines using $\gamma$-amino $\beta$ -keto esters, hexamethylenetetramine and ammonium carbonate.

\section{Results and Discussion}

\section{Design and synthesis}

In order to investigate whether $\gamma$-amino $\beta$-keto esters can undergo Hantzsch type reaction to give desired 1,4-dihydropyridine derivatives, we have synthesized various ethyl esters of $\gamma$ amino $\beta$-keto amino acids from of $N$-protected amino aldehydes in the presence of ethyl diazoacetate and tin chloride (20 mol \%) as a catalyst in DCM, shown in Scheme 1, as per the protocol reported by our group earlier. ${ }^{36}$ All the $N$-protected $\gamma$-amino $\beta$-keto esters were purified through silica column chromatography in good yields before using it for the next step.

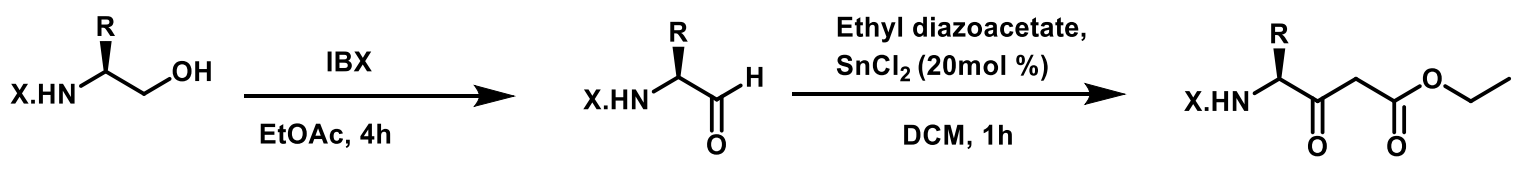
$\mathrm{X}=\mathrm{Boc} / \mathrm{Cbz}$

Scheme 1: Synthesis of $N$-protected $\beta$-keto $\gamma$-amino esters.

Further to go for Hantzsch type reaction we need an aldehyde and a nitrogen source. For the aldehyde source, we have chosen hexamethylenetetramine (HMTA) as it is known for in-situ generation of formaldehyde and for the nitrogen source we went ahead with ammonium carbonate and ammonium acetate for investigating. We have also investigated the reaction yields with various solvents such as water, ethanol and toluene. During the investigation, we have observed that the optimum reaction conditions for best yield were obtained using ethanol as solvent and HMTA and ammonium carbonate combinations at reflux temperature for 2 hours for the complete conversion of $N$-protected $\gamma$-amino $\beta$-keto ester (1a) to obtain 1,4-DHP (2a), shown in Scheme 2.
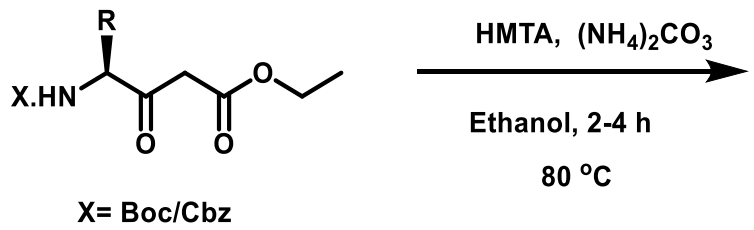<smiles>[X][M]C([R])C1=C(C(=O)OCC)CC(C(=O)OCC)=C([C@@H]([R])N[X])N1</smiles>

Scheme 2: Synthesis of 1,4-dihydropyridines from $N$-protected $\gamma$-amino $\beta$-keto esters. 
Encouraged by the above result for the synthesis of $\mathbf{2 a}$, various hydrophobic $N$-protected $\gamma$ amino $\beta$-keto esters were synthesized (1b-1f) and kept for the reaction in ethanol to obtain desired 1,4-DHPs, shown in Table 1. Later to investigate the interference of side-chain functionalities and different amino acid protecting groups in this reaction, $(N)$ Cbz-protected $\beta$ keto $\gamma$-amino ester $(\mathbf{1 g})$ were synthesized and subjected under the same reaction condition to obtain product $\mathbf{2 g}$. It is worth noting that the reaction is compatible with various hydrophobic side chains and amine protecting groups for the condensation of $\beta$-keto esters of various amino acids to synthesize 1,4-DHPs. All 1,4-DHPs products were isolated in good yields after purification from silica gel column chromatography using hexane and ethyl acetate as solvent systems. Later we kept them for crystallization in Ethyl acetate and x-ray quality single crystal was obtained for 2(b), 2(e) and 2(f). The crystal structure of 2(f) is shown in Figure 2. The crystal structure shows the pyridine ring exists in planer conformation in all of the above. As per the reports in the literature, if no substitution is there at the para position the pyridine ring shows planer structure, which exactly matches our observations in the synthesized amino acidfunctionalized 1,4-DHPs.

Inspired by this result, we thought of investigating the role of substitution at the para position in a conformational change of the pyridine ring and we thought of synthesizing para-substituted 1,4-DHP. For the above purpose, we have chosen $\mathbf{1}(\mathbf{h})$ as $\gamma$-amino $\beta$-keto ester and for the para substitution, we have chosen benzaldehyde as aldehyde source keeping the rest of the reaction condition unchanged to obtain 2(h), shown in Scheme 3. We have observed the complete conversion in 4 hours. Later we purified the product $\mathbf{2}(\mathbf{h})$ through column chromatography characterized by mass and kept it for crystallization in ethyl acetate. We have observed x-ray quality single crystal for 2(h) shown in Figure 3. From the crystal structure, we wonderfully observed the puckered conformation of 1,4-DHP with substitution at the para position hence matches with the literature observations. As we just want the product 2(h) for studying the role of substitution at the para position in conformation and thus, synthesizing and characterization other para-substituted DHP's of this series is beyond the scope of this paper.

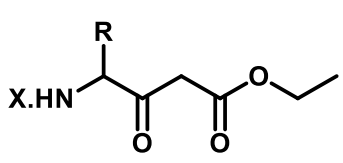

$\mathrm{X}=\mathrm{Boc} / \mathrm{Cbz}$

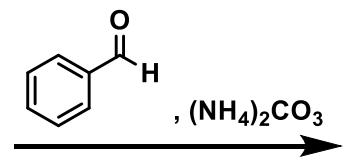

Ethanol, $4 \mathrm{~h}$

$80^{\circ} \mathrm{C}$

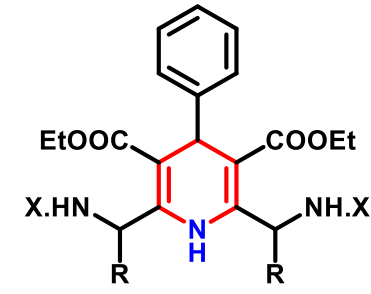

Scheme 3: Synthesis of para-substituted 1,4-dihydropyridine from $N$-protected $\gamma$-amino $\beta$-keto esters. 
Table 1: List of $\gamma$-amino $\beta$-keto esters and their respective symmetrical 1,4dihydropyridine.

(b) (a)

Table 2: List of $\gamma$-amino $\beta$-keto esters and their respective para-substituted 1,4dihydropyridine.

Entry




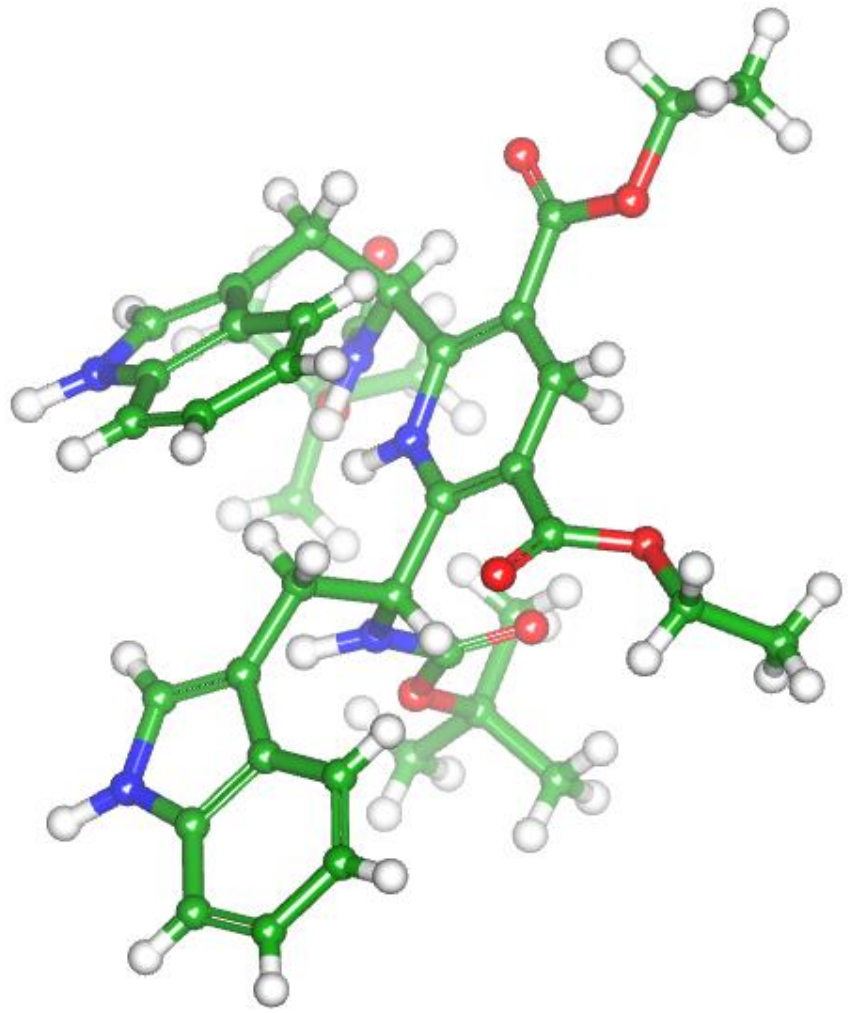

(a)

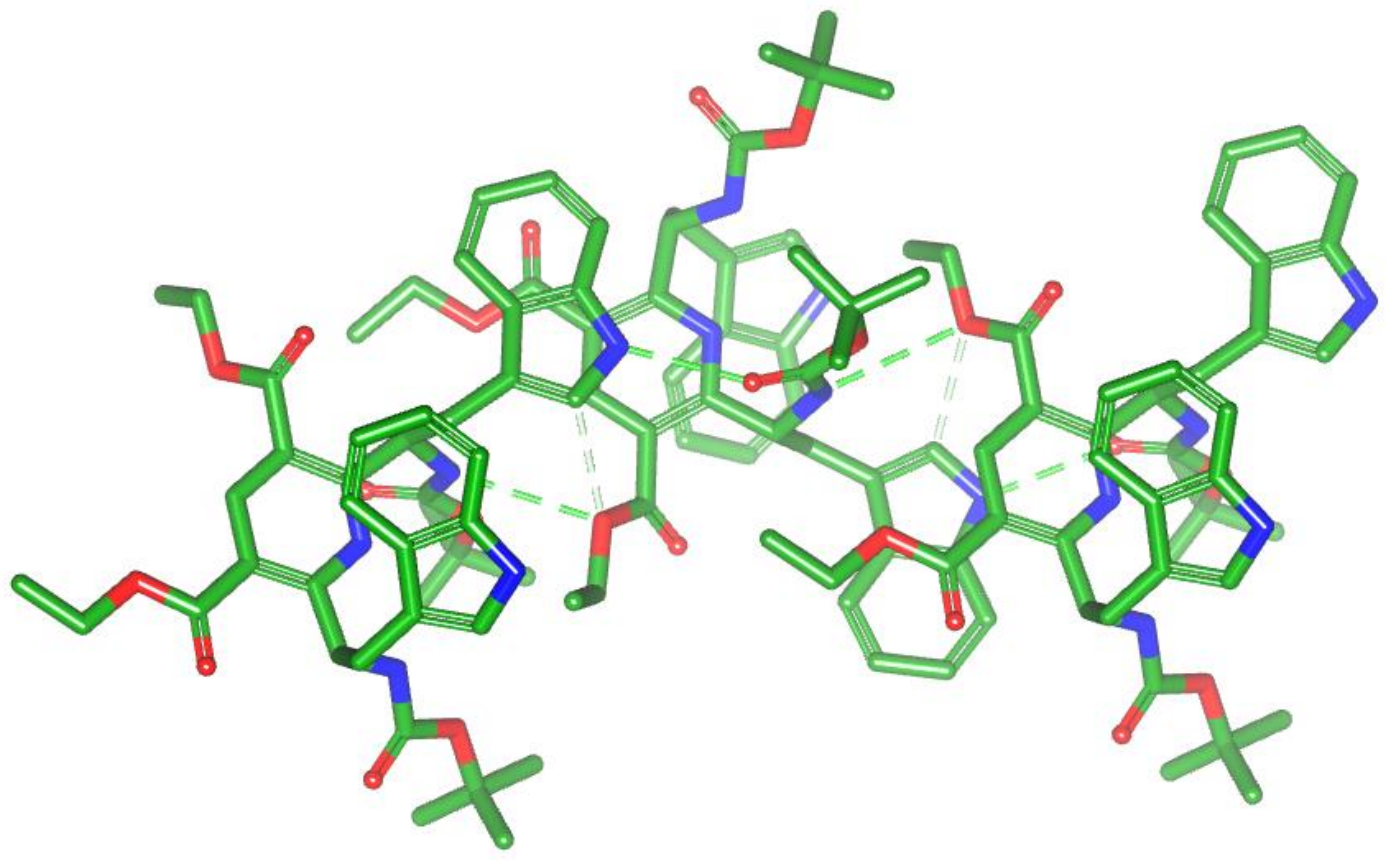

(b)

Figure 2: (a) X-ray structure of compound 2(h) and (b) H-bonding patterns of compound 2(h). 


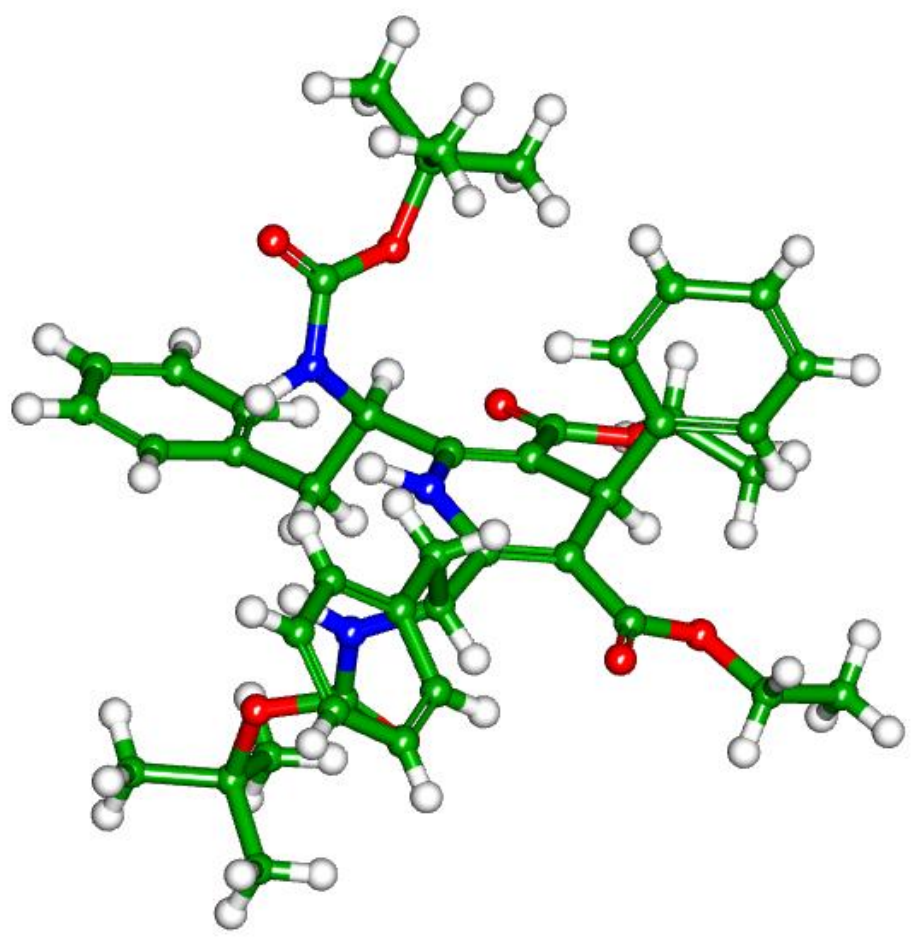

(a)

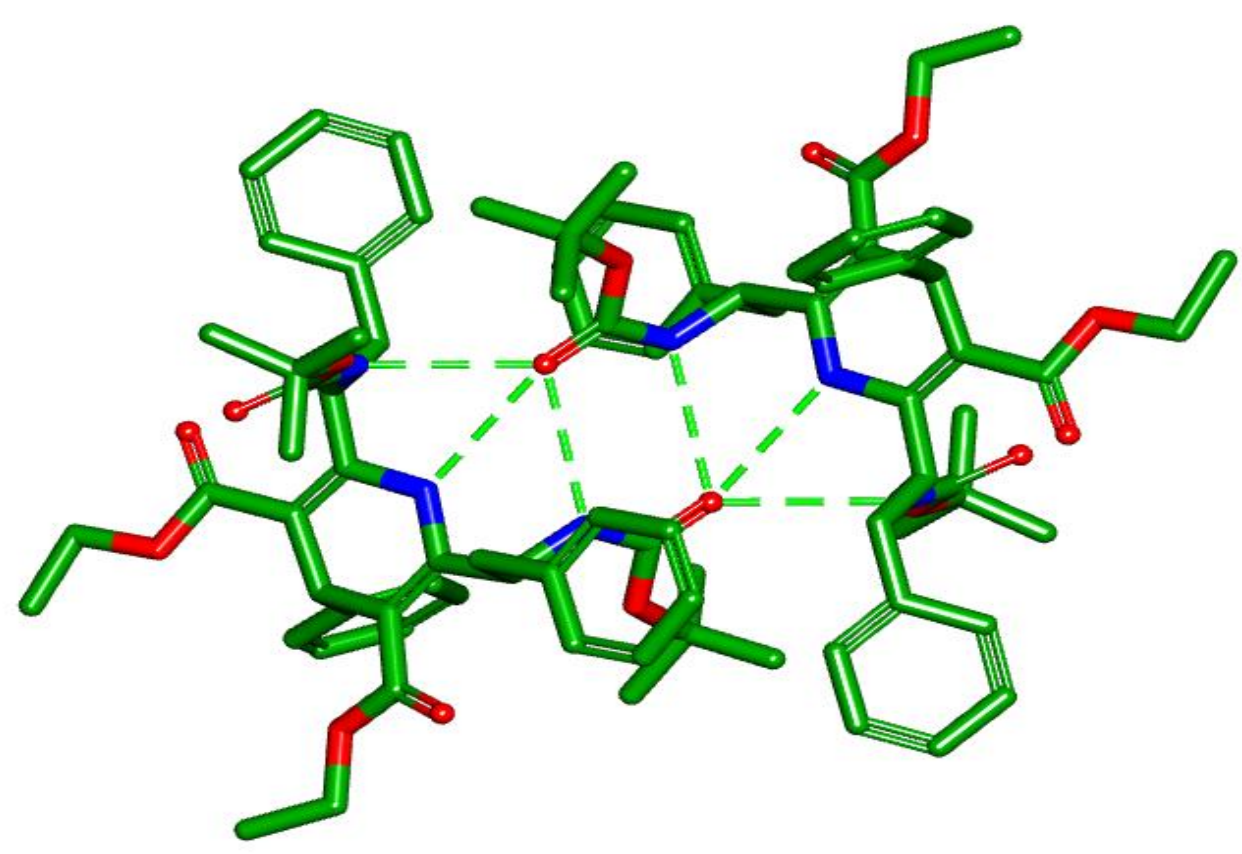

(b)

Figure 3: (a) X-ray structure of compound 2(f) and (b) H-bonding patterns of compound 2(f). 


\section{Conclusion}

In summary, we have proposed an efficient catalyst-free procedure for the synthesis of 1,4dihydropyridines from various amino acids with many functionalities through a one-pot Hantzsch reaction with satisfactory yields of 70-80\%. The protocol is neat and clean. Through this protocol, it is possible to introduce amino acid side-chains in 1,4-dihydropyridines. The hydrogen transferability of these new 1,4-dihydropyridines and medicinal properties will be investigated in due course of time.

\section{References}

[1] M. A. T. Blaskovich, J. Med. Chem. 2016, 59, 10807-10836

[2] J. Paradowska, M. Stodulski, J. Mlynarski, Angew. Chem. Int. Ed. 2009, 48, 4288 - 4297

[3] F. Javier Sardina, H. Rapoport, Chem. Rev. 1996, 96, 6, 1825-1872

[4] A. Preciado, P. G. Williams, J. Org. Chem. 2008, 73, 9228-9234

[5] a) D. Seebach, J. L. Matthews, Chem. Commun. 1997, 21, 2015. (b) D. Seebach, A. K. Beck, D. J. Bierbaum, Chem. Biodiversity. 2004, 1, 1111.

[6] a) Hintermann, T.; Gademann, K.; Jaun, B.; Seebach, D. Helv. Chim. Acta 1998, 81, 893. (b) Hanessian, S.; Luo, X.; Schaum,R.; Michnick, S. J. Am. Chem. Soc. 1998, 120, 8569.

[7] W. Khan, S. Muthupandian, S. Farah, N. Kumar, A. J. Domb, Macromol. Biosci. 2011, 11, $1625-1636$

[8] (a) B. Loev, M.M. Goodman, K.M. Snader, R. Tedeschi, E. Macko, J. Med. Chem., 1974, 17, 956-965. (b) A.M. Triggle, E. Shefter, D.J. Triggle, J. Med. Chem., 1980, 23, $1442-$ 1445. (c) R. Fossheim, K. Svarteng, A. Mostad, C. Romming, E. Shefter, D.J. Triggle, J. Med. Chem., 1982, 25, 126-131. (d) R.A. Janis , D.J. Triggle , J. Med. Chem., 1983, 26, 775-785. (e) M. Schramm, G. Thomas, R. Towart, G. Franckowiak, Nature, 1983, 303, 535. (f) G.M. Reddy, M. Shiradkar, A.K. Chakravarthy, Curr. Org. Chem., 2007, 11, $847-$ 852. (g) R. Miri, A. Mehdipour, Bioorg. Med. Chem., 2008, 16, 8329-8334.

[9] (a) P.L. McCormack, A.J. Wagstaff, Drugs, 2003, 63, 2327-2356. ( b) N. Edraki, A.R. Mehdipour, M. Khoshneviszadeh, R. Miri, Drug Discovery Today, 2009, 14, 1058-1066. (c) P. Ioan, E. Carosati, M. Micucci, G. Cruciani, F. Broccatelli, B.S. Zhorov, A. Chiarini, R. Budriesi, Curr. Med. Chem., 2011, 18, 4901-4922. (d) E. Carosati, P. Ioan, M. Micucci, F. Broccatelli, G. Cruciani, B.S. Zhorov, A. Chiarini, R. Budriesi, Curr. Med. Chem., 2012, 19, 4306-4323. (f) P. A. Datar and P. B. Auti, J. Comput. Methods Mol. Des., 2012, 2, 85- 
91. (g) R. Bansal, G. Narang, C. Calle, R. Carron, K. Pemberton, A. L. Harvey, Drug Dev. Res., 2013, 74, 50-61. (h) M. Martın-Martınez, F. L. Perez-Gordillo, D. Alvarez de la Rosa, Y. Rodriguez, G. Gerona-Navarro, R. Gonzalez-Muniz, M.-M. Zhou, J. Med. Chem., 2017, 60, 2629-2650.

[10] (a) A. E. Abdalla, D.Tirzite, G. Tirzitis, J. P. Roozen, Food. Chem., 1999, 66, 189-195. (b) G. Prasanthi, K. V. S. R. G. Prasad, K. Bharathi, Eur. J. Med. Chem., 2013, 66, 516.

[11] A. Ryckebusch, R. Deprez-Poulain, L. Maes, M. A. Debreu-Fontaine, E. Mouray, P. Grellier and C. Sergheraert, J. Med. Chem., 2003, 46, 542-557.

[12] (a) R. Simsek, Y. Altas, C. Safak, U. Abbasoglu and B. Ozçelik, Farmaco, 1995, 50, 893-894. (b) N. Fokialakis, P. Magiatis, I. Chinou, S. Mitaku and F. Tillequin, Chem. Pharm. Bull., 2002, 50, 413-414. (c) K. Sirisha, D. Bikshapathi, G. Achaiah and V. M. Reddy, Eur. J. Med. Chem., 2011, 46, 1564-1571. (d) Y. L. N. Murthy, A. Rajack, M. T. Ramji, J. J. Babu, C. Praveen, K. A. Lakshmi, Bioorg. Med. Chem. Lett., 2012, 22, 6016.

[13] A. K. Chhillar, P. Arya, C. Mukherjee, P. Kumar, Y. Yadav, A. K. Sharma, V. Yadav, J. Gupta, R. Dabur, H. N. Jha, A. C. Watterson, V. S. Parmar, A. K. Prasad, G. L. Sharma, Bioorg. Med. Chem., 2006, 14, 973.

[14] P. Beagley, M. A. L. Blackie, K. Chibale, C. Clarkson, R. Meijboom, J. R. Moss, P. J. Smith and H. Su, Dalton Trans., 2003, 3046-3051.

[15] (a) J.-1. Jiang, A. M. v. Rhee, L. Chang, A. Patchornik, X.-d. Ji, P. Evans, N. Melman, K. A. Jacobson, J. Med. Chem., 1997, 40, 2596. (b) J.-1. Jiang, A.-H. Li, S.-Y. Jang, L. Chang, N. Melman, S. Moro, X.-d. Ji, E. B. Lobkovsky, J. C. Clardy, K. A. Jacobson, J. Med. Chem., 1999, 42, 3055. (c) R. R. Poondra, R. V. Nallamelli, C. L. T. Meda, B. N. V. Srinivas, A. Grover, J. uttabathula, S. R. Voleti, B. Sridhar, M. Pal, K. V. L. Parsa, Bioorg. Med. Chem.Lett., 2013, 23, 1104. (d) T. R. Reddy, G. R. Reddy, L. S. Reddy, C. L. T. Meda, K. V. L. Parsa, K. S. Kumar, Y. Lingappa, M. Pal, Eur. J. Med. Chem., 2013, 62, 395.

[16] (a) P. Fossa, L. Mosti, G. Menozzi, C. Marzano, F. Baccichetti and F. Bordin, Bioorg. Med. Chem., 2002, 10, 743-751. (b) H. Niaz, H. Kashtoh, J. A. J. Khan, A. Khan, A. Wahab, M. T. Alam, K. M. Khan, S. Perveen, M. I. Choudhary, Eur. J. Med. Chem.,2015, 95, 199.

[17] (a) A. Hilgeroth, M. Wiese and A. Billich, J. Med. Chem., 1999, 42, 4729-4732. (b) A. Hilgeroth, A. Billich and H. Lilie, Eur. J.Med. Chem., 2001, 36, 367-374. (c) F. Lentz, M. Hemmer, N. Reiling, A. Hilgeroth, Bioorg.Med. Chem. Lett., 2016, 26, 5896. 
[18] (a) R. León, C. d. 1. Ríos, J. Marco-Contelles, O. Huertas,X. Barril, F. J. Luque, M. G. López, A. G. García,M. Villarroya, Bioorg. Med. Chem., 2008, 16, 7759. (b) V. Alptüzün, M. Prinz, V. Hörr, J. Scheiber, K. Radacki, A. Fallarero, P. Vuorela, B. Engels, H. Braunschweig, E. Erciyas, U. Holzgrabe, Bioorg. Med. Chem., 2010, 18, 2049.

[19] (a) L. R. Morgan, B. S. Jursic, C. L. Hooper, D. M. Neumann, K. Thanagaraj and B. LeBlanc, Bioorg. Med. Chem. Lett., 2002,12, 3407-3411. (b) B. Voigt, C. Coburger, J. Monar, A. Hilgeroth, Bioorg.Med. Chem., 2007, 15, 5110. (c) C. Coburger, J. Wollmann, M. Krug, C. Baumert, M. Seifert, J. Molnár, H. Lage, A. Hilgeroth, Bioorg.Med. Chem., 2010, 18, 4983. (d) K. Sirisha, M. C. Shekhar, K. Umasankar, P. Mahendar,A. Sadanandam, G. Achaiah, V. M. Reddy, Bioorg. Med. Chem., 2011, 19, 3249. (e) C. Baumert, M. Günthel, S. Krawczyk, M. Hemmer, T. Wersig, A. Langner, J. Molnár, H. Lage, A. Hilgeroth, Bioorg. Med. Chem., 2013, 21, 166. (f) S. Valente, P. Mellini, F. Spallotta, V. Carafa, A. Nebbioso, L. Polletta, I. Carnevale, S. Saladini, D. Trisciuoglio, C. Gabellini, M. Tardugno, C. Zwergel, C. Cencioni, S. Atlante, S. Moniot, C. Steegborn, R. Budriesi, M. Tafani, D. Del Bufalo, L. Altucci, C. Gaetano and A. Mai, J. Med. Chem., 2016, 59, 1471-1491.

[20] K. Cooper, M. J. Fray, M. J. Parry, J. Med. Chem., 1992, 35, 3115.

[21] (a) B. Desai, D. Sureja, Y. Naliapara, A. Shah, A. K. Saxena, Bioorg. Med. Chem., 2001, 9, 1993. (b) P. S. Kharkar, B. Desai, H. Gaveria, B. Varu, R. Loriya, Y. Naliapara, A. Shah, V. M. Kulkarni, J. Med. Chem., 2002, 45, 4858. (c) M. Khoshneviszadeh, N. Edraki, K. Javidnia, A. Alborzi, B. Pourabbas, J. Mardaneh, R. Miri, Bioorg. Med. Chem., 2009, 17, 1579. (d) A. R. Trivedi, D. K. Dodiya, B. H. Dholariya, V. B. Kataria, V. R. Bhuva, V. H. Shah, Bioorg. Med. Chem.Lett., 2011, 21, 5181.

[22] (a) N. Pedemonte, T. Diena, E. Caci, E. Nieddu, M. Mazzei, R. Ravazzolo, O. ZegarraMoran, L. J. Galietta, Mol. Pharmacol., 2005, 68, 1736.

[23] C. E. Muller, Curr. Top. Med. Chem., 2003, 3, 445.

[24] (a) G. Tenti, J. Egea, M. Villarroya, R. Leon, J. C.Fernandez, J. F. Padın, M. Vellaisamy Sridharan, T. Ramosa, J. C. Menendez, Med. Chem. Commun., 2013, 4, 590. (b) V. Klusa, Drugs Fut., 1995, 20, 135.

[25] (a) R.M. Kellogg, Angew. Chem., Int. Ed. Engl. 1984, 23, 782-794. (b) S. Yasui, A. Ohno, Bioorg. Chem., 1986, 14, 70-96. (c) X. Q. Zhu, Y. Liu, B.J. Zhao, J.P. Cheng, J. Org. Chem., 2001, 66, 370-375. (d) Z. Zhang, J. Gao, J.-J. Xia and G.-W. Wang, Org. Biomol. Chem., 2005, 3, 1617-1619. (e) R. I. Storer, D.E. Carrera, Y. Ni, D.W. MacMillan, J. Am. Chem. Soc., 2006, 128, 84-86. (f) J. B. Tuttle, S. G. Ouellet, D.W. 
MacMillan, J. Am. Chem. Soc., 2006, 128, 12662-12663. (g) S. G. Ouellet, A.M. Walji, D.W. MacMillan, Acc. Chem. Res., 2007, 40, 1327-1339. (h) Q. Kang, Z.A. Zhao, S.L. You, Org. Lett., 2008, 10, 2031-2034. (i) G. Li and J. C. Antilla, Org. Lett., 2009, 11, 1075-1078. (j) X.-F. Zhou, P.-F. Wang, Y. Geng and H.-J. Xu, Tetrahedron Lett., 2013, 54, 5374-5377. (k) L. A. Chen, W. Xu, B. Huang, J. Ma, L.Wang, J. Xi, K. Harms, L. Gong and E. Meggers, J. Am. Chem. Soc., 2013, 135, 10598-10601.

[26] A. Hantzsch, Justus Liebigs Ann. Chem., 1882, 215, 1.

[27] (a) T. Sirijindalert, K. Hansuthirakul, P. Rashatasakhon,M. Sukwattanasinitt and A. Ajavakom, Tetrahedron, 2010, 66 , 5161-5167.(b) J. Yang, C. Wang, X. Xie, H. Li and Y. Li, Eur. J. Org. Chem., 2010, 4189-4193.

[28] J. Moreau, A. Duboc, C. Hubert, J.-P. Hurvois and J.-L. Renaud, Tetrahedron Lett., 2007, 48, 8647-8650. (b) C.G. Evans, J.E. Gestwicki , Org. Lett., 2009, 11, 2957-2959.

[29] A. Debache, W. Ghalem, R. Boulcina, A. Belfaitah,S. Rhouati and B. Carboni, Tetrahedron Lett., 2009, 50, 5248-5250.

[30] (a) J.L. Donelson, R.A. Gibbs, S.K. De, J. Mol. Catal. A Chem., 2006, 256, 309-311.

(b) S. Kikuchi, M. Iwai, H. Murayama and S. Fukuzawa, Tetrahedron Lett., 2008, 49, 114116.

[31] S. Ko, M. N. V. Sastry, C. Lin, C.F. Yao, Tetrahedron Lett., 2005, 46, 5771.

[32] (a) J. Jiang, J. Yu, X.-X. Sun, Q.-Q. Rao and L.-Z. Gong, Angew. Chem., Int. Ed., 2008, 47, 2458-2462. (b) C. A. Sperger and K. T. Wanner, Tetrahedron, 2009, 65, 5824-5833. (c) D. L. Comins and A. H. Abdullah, J. Org. Chem., 1982, 47,4315-4319. (d) D. L. Comins, A. H. Abdullah and R. K. Smith, Tetrahedron Lett., 1983, 24, 2711-2714. (e) A. Kumar, R.A. Maurya, Tetrahedron, 2007, 63, 1946-1952. (f) C.G. Evans, J.E. Gestwicki, Org. Lett. 2009, 11, 2957-2959.

[33] (a) G. Sabitha, G.S. Reddy, Ch. S. Reddy, J. S. Yadav, Tetrahedron Lett., 2003, 44, 4129. (b) G. Sabitha, K. Arundhathi, K. Sudhakar, B. S. Sastry, J. S. Yadav, Synth. Commun., 2009, 39, 2843-2851.

[34] Y.F. Li, H.Z. Yang, J. Mol. Catal. A: Chem., 2006, 258, 133.

[35] M. Ganesh Kumar, K. Veeresh, S. A. Nalawade, R. V. Nithun, H. N. Gopi, J. Org. Chem. 2019, 84, 15145-15153

[36] A. Bandyopadhyay, H. N. Gopi, Org. Biomol. Chem. 2011, 9, 8089-8095

[37] A. Bandyopadhyay, A. Malik, M.G. Kumar, H.N. Gopi, Org. Lett., 2014, 16, 294-297.

[38] M.G. Kumar,V.J. Thombare, R.D. Bhaisare, A. Adak, H.N. Gopi, Eur. J. Org.

Chem. 2015, 1, 135-141. 


\section{Acknowledgement}

We thank the Indian Institute of Science Education and Research, Pune, and the Department of Science and Technology, Govt. of India, for financial support. A. A and P. K are thankful to Dr. H. N. Gopi, Department of Chemistry, IISER-Pune for the guidance and support.

Supporting Information Available: Experimental procedures, compound characterization, and crystallographic information. 